\title{
A Quantitative Analysis of Words with Implied Negation in Semantics
}

\author{
Yun Ding \\ Qingdao University of Science and Technology, China
}

\begin{abstract}
This thesis aims at making a quantitative analysis on the application of words with implied negative meaning in English. With the help of some scientific research methods such as SNOBL4 and SPSS software, a quantitative computerized analysis on the frequency and distribution of implied negatives is made among different written English corpora: Browna, BrownB, Loba, T4 and Nec etc. The result shows that implied negation is widely applied in written English, with its frequency determined by the specific style of the article; Therefore, if implied negatives are employed properly according to the style of the article, the sentence pattern will be greatly varied with it language more vivid as well
\end{abstract}

Index Terms - negative meaning semantic quantitative analysis

\section{INTRODUCTION}

Over the centuries, there has been tremendous scholarly and philosophical interest in negation. This preoccupation is reflected in Seifert and Welt's Basic Bibliography of Negation in Natural Language (1987), which lists some 3200 titles in over 200 languages. The fact that much of the literature is in English means that many problems of negation in English have been treated, although this is of course coincidental. Many problems have attracted particular attention, and one may even speak of a canon of problems to which scholars have been drawn, generation after generation. Such problems typically have to do with negative scope when negation and quantifiers co-occur (as in All boys didn't leave.), neg-raising (as in I don't think he's coming) or double or multiple negation (I don't know nothing no more), depending on the particular interests and backgrounds of individual scholars. In this paper, I treat negation in English, but I'll focus on implied negation which has not been given too much attention in the literature, even though this phenomenon is ubiquitous. However, I believe they are important for our understanding of negation in English and of negation in natural language in general. I deal with the use of implied negation in written language (different corpora), and I address the question of how and why we use implied negation from a quantitative point of view.

In order to provide solid and tangible data for the present analysis, I employ several corpora for my analysis: LOBA, BROWNA, BROWNB, MEE, NEC, and T4.

One internationally renowned text database, the LOB Corpus consists of 500 texts of about 2000 words each from British Written material published in 1961. A wide range of material is represented, including newspaper articles, fictions, religious writing and so forth. I utilize the first part of it, LOBA for the analysis. The BROWN Corpus was made up of 500 texts, about one million words of written American English in 1961 as well. The distribution of text categories is similar to that of LOB Corpus. In my paper, the first two parts, BROWNA and BROWNB are employed. MEE and NEC represent Marine Engineering English and Nautical English respectively. Those established corpora are attributable to the work and cooperation of the former graduates. T4 Corpus is a sub-corpus of the JDEST Corpus which was built by the scientific English center of Shanghai Communication University. It contains materials sampled from various publications of English -speaking countries covering various subjects of science and technology including mechanism, electronics, physics and so on.

In the process of this research, modern statistical method was adopted. To obtain the data of relevant frequency, a Visual FoxPro program was used to break the corpus into individual sentences. In order to get those sentences with negative words, another Visual FoxPro program was used. For quantitative linguistic investigation, the knowledge of statistics is very necessary. The Chi-square test, extensively used in my research, is a widely used non-parametric test in linguistic statistics, which helps us to compare the distribution of certain linguistic features in two or more samples. In my thesis, the computer is used to make the research work much easier by operating SPSS (the Statistical Package for Social Science), a package for the statistical research of texts.

Procedures for searching and handling implied negation in the six corpora are as followed:

With the application of computer software, especially SPSS and SNOBOL4, raw data on the distribution of implied negatives among those databases are to be extracted. By running SPSS and SNOBL4 programs, gross frequencies from the six corpora, namely BROWNA, BROWNB, LOBA, MEE, NEC, and T4, are obtained. Gross frequencies refer to the results obtaining by running programs that need manual sorting and correction.

Most analysis in this paper relied on computer programs, which produced precise empirical data. In some cases, computer programs cannot fulfill the aim, such as selecting out sentences without negative meaning even though they contain inherent negative words (as double negation). So manual works as well observation method had to be involved. 


\section{THEORETICAL BACKGROUND}

According to Longman dictionary of Language Teaching, negation is contradicting the meaning or part of the meaning of a sentence. The main negator in English is not, often in its contracted form n't and combined with an auxiliary. Quirk Randolph, el, (1985) in A Comprehensive Grammar of English Language, deals with negation as a syntactic process within the clause. They classify negation into three types: (Quirk, 1985)

a. Clause Negation, through which the whole clause is syntactically treated as negative (1).

(1) I have finished. (Positive) I have not finished. (Negative)

b. Local Negation, in which one constituent (not necessarily a clause element) is negated, as in sentence (2)

(2) They made some not unintelligent observations.

c. Predication Negation, a minor type applying only after certain auxiliaries, in which the predication is negated (3):

(3) They may not go swimming. (They are allowed not to go swimming)

In order to make a further understanding of negation, three concepts need to be drawn a distinctive line, negative sentence, negative form and negative meaning.

\section{i) Negative sentence}

It belongs to grammatical category which refers to a sentence that contains negative words like not, never, or nowhere. The list of negative words in English is: neither, never, no nobody, none, no one, nor, not, nothing, nowhere. They are also called Full negatives. In addition, we can form a negative sentence with Quasi negatives, such as harily, scarcely, seldom, barely, few, little, etc. The adverbs of negation convey the idea that the action or state being descried "usually" does not or did not happen or exist, but could have occasionally. They are negative, though not in the absolute sense as sentences with not and never are.

A sentence is called a negative sentence in that it must share the following syntactic features:

a) It is followed by positive checking tag questions:

(4) She doesn't work hard, does she?

b) It is followed by negative tag clauses, with additive meaning:

(5) I haven't finished, \{and neither\} have you.

c) It gives rise to auxiliary-subject inversion when applied to the initial position.

(6) Never have I thought of such a strange idea.

(7) Little need I dwell upon the joy of that reunion.

d) It is followed by nonassertive items, such as ever, any

(8) He won't notice any change in you.

\section{ii) Negative form}

Negative form marks a clause as negative, even if the word not $(-n$ 't) does not occur in it. Though varied in actual patterns, negative form can be primarily divided into two categories: one is with negative words such as not, no, never, nor, and so on, and the other with negative affixes, such as un-ab-, dis-, il-, im-, ir-, in-, mis-, non-, -less etc. In certain contexts, clauses with affixal negation are approximately synonymous with clauses negated by the clause negator not. For example:

(9) That is not true. $=$ That is untrue.

(10) You are not careful. $=$ You are careless

(11) She is not active. $=$ She is inactive.

\section{iii) Negative meaning}

It differs from the former two in that it means to negate a situation, whatever forms it may take. That is to say, it can be represented in various forms. Mainly there are two ways to achieve negative meaning. First, it can be achieved by using negative sentences. E.g.

(12) I don't want anything else. (Negative sentence indicating negative meaning)

Second, it can be achieved through words negative in meaning.

a) Quasi negative words, like hardly, barely, seldom, few, little, etc. e.g.

(13) The dormitories could barely house one hundred students.

(14) He hardly ever goes to bed before midnight.

b) Words with negative affixes as those mentioned in (ii) above.

c) Implied negatives, such as fail, prevent, reluctant, deny, absent, etc. e.g.

(15) She refused to accept his gift.

(16) She is too excited to say anything.

Such sentences are in affirmative forms but they can also be employed to express negative meaning. There is no doubt that many other types of this kind can be found other than the above mentioned, upon which I shall dwell in detail in this paper.

So far, it is clear that negative sentence is not the same as negative form when negative meaning is involved. Sentences (13) and (14) negated respectively by Quasi negative words barely and hardly are negative sentences and furthermore they are negative in meaning and behavior although they do not appear negative in forms. Furthurmore, negative meaning is not always indicated by negative form. Sentences (15) and (16) imply negative meaning without any negative form. 
After making the three concepts clear, it is necessary to clarify the types of negation. As for the classification of negation, linguists who have researched into words implying negative sentences are of the view that these words can be classified in the following ways.

(i) Full negatives: no, not, none, never, nothing, nobody, nowhere, neither, nor

(ii) Absolute negatives: not at all, by no means, in no way, nothing short of, etc.

(iii) Quasi negatives: hardly, scarcely, seldom, barely, few, little

(iv) Partial negatives: not every, not all, not much, not many, not always, etc.

(v) Words with negative implication: fail, without, beyond, until, unless, lest, ignorant, refuse, neglect, absence, instead of, etc.

In terms of negative formation, there are two major categories. One is grammatical, the other semantic.

First, grammatically it refers to sentences containing negative words, such as not, no, neither never, none, nobody, nothing, by no means, etc. That is, that is obvious negator no or not in the sentence as in sentences (1)-(8) above.

Second, semantically it relates to sentences containing words with negative meaning, such as few, little, far from, fail to and so on. There is no obvious negator in the sentences as in (13)-(16)

According to the two categories, negation is classified five types: general negation, special negation, negation in forms and in meaning, negation in form but not in meaning, and negation in meaning but not in form.

General Negation is the most common form of negation. In this case, a simple positive sentence (or clause within a complex sentence) is negated by inserting the clause negator not between the operator, and the predication, thus making the whole sentence negative. The operator here is the first auxiliary verb of a complex verb phrase or with either or (especially in British English) stative have as the verb in a simple sentence. Thus the negation of They are noisy is They are not noisy, and the negation of He has enough money is He has not enough money. More examples:

(17) I have not told the students.

(18) You mustn't go to work today.

(19) Peter cannot swim.

If an operator is not present in a positive sentence, it can be made by 'creating' the auxiliary do as an operator. This is referred to as the do-construction or do-support. E.g. (20) They like to watch TV. They do not (don't) like to watch TV.

In addition, absolute negator never can also be used to negate verbs and made the whole sentence negated, which is referred to as General negation as well, e.g.

(21) I will never go to visit him.

Special Negation is contained in sentences that one constituent (not necessarily a clause element) is negated. The negation may be accomplished either by using a negative word such as no or by negating a word or phrase except the verbs. So Special Negation is more complicated than General Negation not only in formation but also in meanings:

a. Special Negation with general negator not.

The negative word not can be used with almost any word or word group in a clause to achieve Special Negation, with a view to being more forceful, careful, polite or hesitant. For example, it can be put to use with nouns, adjectives, adverbs, prepositional phrase and quantifiers. E.g.

(22) The policeman told the boys not to play with fire.

b. Special Negation with absolute negator never. E.g.

(23) He warned the children never to play with fire.

c. Special Negation with no and no-words:

(24) I have no time to chat with you now.

(25) I saw nobody in the street.

d. Special Negation with prefixes un-, in-, dis- non- and suffixes, such as -less etc before or behind the negated words:

(26) It is impossible for you to finish the task in two days.

Negation in forms and in meaning is the general and most common way of making a negative state in English. On basis of the semantic meanings and functions that negators perform in different contexts, there are full negation, partial negation transferred negation and so on:

a. Full Negation signifies total no-existence of men, matter, time, place, and so on. In most cases, the negation is constituted by using absolute negative words or other synonymous expressions:

(27) Neither of them can swim.

(28) He was no way responsible for that accident.

(29) A dog cannot fly.

b. Partial Negation negates a part of the whole. Therefore, when it is used together with pronouns, adjectives, adverbs, numerals that carry meaning of universal like All, Every, and Both; adverbs like Always, Often, Quite, and Entirely, not usually does not result in absolute negation but partial affirmation and partial negation. E.g.

(30) Not many of us will go there tomorrow.

(31) Money is not everything.

(33) All is not gold that glitters.

c. Transferred Negation: This form of negation is particularly common in informal style. It is the transfer of the 
negative from a subordinate clause (generally a that clause) when semantically it belongs to the matrix clause. (Quirk, 1985)

(34) I don't think it's a good idea. (I think it isn't a good idea)

(35) I don't believe I've met you before. (I believe I haven't met you before.)

Negation in form but not in meaning mainly refers to double negation, which is constructed when no, not and so on are used together with other words expressing negative meaning. E.g.

(36) Nobody has nothing to eat. = Everyone has something to eat.

(37) No man is without enemy. = Everyone has enemy.

Besides. There are some other patterns negative in form but not in meaning:

(38) He didn't speak any word until he saw his mother. (Not...until)

(39) He likes not only Chinese but also English. (Not only...but also)

Negation in meaning but not in forms is called by some grammarians Indirect Negation or Implied Negation. (Quirk, 1985). There are dozens of English words and phrases, though do not look like negative words in forms, are negative in meaning and are widely applied. If we ignore this fact, we would not be able to comprehend negative statement adequately, whether from Chinese to English or vice versa. So the original (either Chinese or English) must be studied carefully to grasp its dialectical approach to acquire an accurate comprehension; also it is of vital importance to see how the thought of original can be best rendered into idiomatic English.

Thus we know that implied negation is one branch of negation, which refers to those sentences with negative meaning but in affirmative form from semantic point of view.

\section{TyPES OF IMPLIED NEGATION IN WORDS AND STRUCTURE}

As for the vocabulary and sentence structures, it is impossible for me to cover all in English. Therefore, I will mainly deal with those that are frequently discussed by grammarian and those regularly used in English. All words and structures analyzed in next chapter are derived from various grammar books related to this topic.

Classification of Words with Implied Negative meaning

There are a large number of words with negative meanings (Klima,1964). On the basis of their attribute, they can be divided into the following groups:

\section{Noun or noun phrase with negative meaning.}

These kinds of nouns include: failure, lack, shortage, refusal, negation, ignorance, absence, reluctance, neglect loss, denial and exclusion. Besides, when some noun is combined with preposition from, it also can imply negative meaning, such as freedom from, deviation from, prevention from, protection from and departure from. E.g.

(1) \#8 **** FAILURE $* * * *<4790$ 0066IM96071965 Success is important because of the failure of the previous attempt to adopt an HNS Convention. >

(2) \#11 **** LACK $* * * *<16140058$ FR92011318 One factor is the lack of physical breaking facilities, suitable yards and downstream logistics to handle the scrap materials. $>$

(3) \#4 **** SHORTAGE $* * * *<1520$ 0058FR92011045 Towards year-end growing cautiousness was again experienced, due to low economic activity and uncertain prospects, shortage of finance and lack of long-term employment, but not without hopes of the economic locomotives getting the steam up in 1992. ... .

(4)\#1512 **** FROM ****<14133 0122NR89100145 For freedom from vibration the propeller must turn in a smooth flow of water. >

(5) \#1 **** IGNORANCE ****<13240 0120sw96030533 Nautical professionals should be competent to ensure that no ship is put at risk through ignorance or inadequate training. >

\section{Verbs of negative meaning.}

There are four kinds of verbs of negative meaning. First type consists of words like fail, miss, escape, defy, baffle, resist, decline, negate, negative, doubt, wonder, lack, grudge, spare, neglect, cease, exclude, ignore, loathe, overlook, deny, and forbid. These words can make a sentence negative in meaning. Negation in this case is called inherent negation. (Zeng, 1993)

(1) \#13 **** FAIL ****<22564 0151PH95121088 Directors can be personally liable if they fail to exercise the skill and expertise that may reasonably be expected of someone in their position, having regard to their capabilities and experience. >

(2) \#1 **** MISSED ****<4172 0064SM96041486 Unfortunately, she missed her opportunity to become the eyes of the Grand Fleet, but the principle if aircraft at sea was now firmly established and moves were afoot to commission more aircraft carriers. >

(3) \#1 *****SPARED ****<\#13 B01 0290 Fortunately it spared us from the usual spate of silly resolutions which in the past have made Georgia look like anything but "the empire state of the South". >

(4) \#2 **** RESIST ****<21405 0150HS96033323 He said that some Justice Act 1993 forbids a manipulation of price-sensitive information, which has not been made public, for personal advantage. >

Second type refers to verbs such as intend, mean, plan, hope, and think. When these verbs are used in past perfective aspect, they can imply negative meaning. E.g.

(1) I had expected that things would turn out like this. (Actually, things didn't turn out like this) 
(2) I had planned to go abroad. (In fact, I didn't go)

The third type of words involves those that can convey negative meaning when they are combined with from, such as refrain \excuse \save \ersuade \protect \revent $k e e p \backslash$ free ...from. E.g.

(1) \#2160********<22611 0151PH95121216 A Policy might be that Board members and employees should refrain from involving themselves in situations which bring them into a conflict of interest with the corporation. >

(2) \#1192 ********<10944 0094nm95040131 We are grateful to those who saved them from the breakers yards - a tribute to their builders and the men who served in them both in war and peace. $>$

The fourth type comprises verb phrases such as give up, lose sight of, shut one's eye to, keep off, keep out, turn a deaf ear to and keep...dark. E.g.

(1) \#3 **** GIVEN UP ****<24197 0154MO96100964 In some cases, such as for whales and dolphins, also for insects generally, despite our continuing efforts we have been unable to find replacement correspondents for those that have given up doing this for us. $>$

(2) \#1 **** LOST SIGHT OF $* * * *<269540157$ BF95120438 I have lost sight of the survival vessel. >

There are other expressions with the same function.

(1)Please keep the news dark. (Don't tell others the news)

Moreover, words like lose, forget, and shun can also indicate negation sometimes. For example,

(1) She forgot to mail the letter. (...didn't mail the letter)

(2) He just lost the train. (...didn't catch the train)

3) The lazy man shunned work. (...didn’t work.)

\section{Adjectives}

The adjectives we often come across are, far from, clear of from, free fromlof, short of, devoid of, absent (from), different from, safe from, a far cry from, alien to, foreign to, Greek to, ignorant, reluctant (to), blind to, dead to, deficient (in), exclusive of, loath, far and few between, and all thumbs. E.g.

(1) \#10**** FAR FROM ****<30061 0176NA94000149 0 Even if berthed alongside or if special moorings are used a ship may be far from secure. $>$

(2) \#1 **** CLEAR OF $* * * *<53260067$ MC94060798 Stand clear of the ropes as they run. >

(3) \#7 **** FREE FROM $* * * *<24635$ 0155ME92010901 Food handlers should be free from communicable diseases. $>$

(4) \#1 **** DEFICIENT ****<27413 0158AC91020885 Where the parties have limited liability and allocated risk by agreement, tort remedies should not be allowed to supersede the parties prior understanding of the consequences of deficient performance. >

Alike sometimes can also be used to express negative meaning. E.g.

(5) All music is alike to me. (I don't understand music at all.)

\section{Adverb}

There are two types of adverbs of negative meaning. First type is defined as Quasi negatives such as hardly, seldom, rarely, scarcely, few and little. E.g.

(1) \#3 **** HARDLY ****<5403 0067MC94060898 Sorry, I can hardly accept the course you advised me steer. >

(2) \#3 **** RARELY ****<4212 0065 CI95110108 Details of her movements were rarely reported and it must be assumed that voyages were largely confined to her home waters. $>$

(3) \#164 **** FEW ****<24749 0155ME92011174 Exercise and boredom Very few seamen aboard ship exercise hard enough to cause them to become breathless or to increase the rate of their heart-beat. >

(4) \#156**** LITTLE $* * * *<300910176$ NA94000282 It should be borne in mind, however, that very little warning of the approach of an intense storm of small diameter may be expected. >

These sentences are usually classified in syntactic negation not lexical one, because co-occurrence tests show that they tend to function like explicit negatives. Therefore, these words will be excluded in the following corpus analysis.

Second type only refers to those individual adverbs or adverbial phrases functioned as adverb such as vainly, in vain, otherwise, the least, least of all the last, the limit and out of the question

(5) \#4948****<0067MC94060133 " I informed the foreman to stop using hooks, but in vain.>

(6) \#9 **** THE LAST ****<\#602 A07 194 "A strike's the last thing I want. >

(7) \#1 **** OUT OF THE QUESTION ****<7576 0073NN89020378 This made trawling out of the question in the areas the Icebergs grounded. >

\section{Preposition}

Some preposition are named negative preposition, such as away from, out of, and off. E.g.

(1) Ann drove away from home. Ann is away from home.

(2) The book fell off the shelf. $\quad$ The book is off the shelf.

(3) Tom got out of the water. $\quad$ Tom is out of water.

The negative prepositions may be defined simply by adding the word not to the corresponding positive preposition: away from (not at), off (not on), out of (not in). (Quirk, 1985)

There are other preposition that possess negative meaning in certain occasion, such as past, above, without, beyond, instead of, against, below, beside, but, except, from, under, within(not beyond), and beneath(not worthy of). E.g. 
(4) \#197**** OFF ****<14468 019RT85B0232 This compulsory piece of equipment monitors the international distress channel automatically while the radio officer is off watch.>

(5) \#23 **** OUT OF $* * * *<4451$ 004DE95B4163 Fuel settling-tanks, being generally placed out of sight, high up in the engine-room, are apt to escape attention until a ship has put to sea and begins to roll. $>$

(6)\#8 **** BEYOND ****<4978 0067MC94060370 I assure you it was beyond my control. >

(7) \#290 **** AGAINST ****<30127 0177NA94000066 LIABILITIES The Third parties may direct a claim against the parties involved in the charter agreement. $>$

Furthermore, some implied negation can be achieved by the combination of preposition and other words, such as at one's wit's end, at the end of one's rope, at the end of one's row at variance with; but for; in default of, in place of, in the dark about, in spite of, in vain, in lieu of, in defect of; out of one's range, out of order, out of plumb, out of practice, out of shape, out of reason, out of sight, out of square, out of sorts, out of hearing, out of common, out of the corners of one's eye, out of ordinary, out of the picture, out of touch with, out of whack, out of fashion, out of politeness, out of one's element, and out of place,.

But for is not used in the sense of exception, but rather that of negative condition:

(8) But for Gordan, we would have lost the match. (if it hadn't been for Gordan....; if Gordan hadn't played as he did...)

\section{Conjunction (mainly subordinators)}

Words in this type include unless (if not), lest, for fear (in order that...should not occur), in case (in order not), and before (rather than).

Unless introduces a negative condition; the unless-clause is usually roughly similar to a negative if-clause. With unless there is a greater focus on the conditions as an exception (only if...not). There are therefore contexts in which the unless-clause cannot occur:

I'll feel much happier if he doesn't come with us.

*I'll feel much happier unless he comes with us.

Here are more examples:

(1) \#86 **** UNLESS $* * * *<28659$ 0165NA94000128 Geographical positions refer to the largest scale chart "unless otherwise stated. >

Negative purpose is expressed in the infinitive clauses by so as not to and in order not to:

(2) Turn the volume down so as not to wake the baby.

(3) I ignored the remark in order not to prolong the dispute.

While in finite clauses it is expressed by in order that...not, but also by specific subordinators: for fear (that)(formal), in case $(\mathrm{BrE})$, or the very formal lest:

(4) They left early for fear (that) they would meet him.

(5) They evacuated the building in case the wall collapsed.

For fear (that) conveys also the meaning of apprehension and requires a modal auxiliary, but in case need not have a modal auxiliary. In (5) there is an implicit negative purpose 'in order that, if the wall collapsed, they would not be affected.' Archaic lest tends to have a modal auxiliary or (esp in AmE) the present subjunctive:

(6) Earthen mounds were being hastily erected lest an attack should be be (esp AmE) launched that night.

Before marks the time before which the situation in the matrix clause applies, but the matrix clause need not be durative: "I started my meal before Adam arrived." But before-clauses are not always true. Nonfactual before-clauses may imply preference, as in (7); or implausibility as in (8): He'll beg for food before he 'll ask his parents'for money. (He won't ask his parents for money; he would rather beg for food than ask his parents for money) (7)

Pigs will fly before he'll become a mathematician. (He will never become a mathematician) (8)

Or the situation in the matrix clause may prevent that in the before-clause from taking place:

He died before writing a will.

(9) Sally stopped Ted before he had a chance to reply. (Ted didn't have a chance to reply)

Some before-clause may be interpreted as either factual or nonfactual:

(10) You still have time before you have any need to register. (You don't have any need to register now)

(11) I sent a donation before I was asked to.

The implication can be paraphrased by the negative conditional clause: Give me some money. If you don't give me some money, I'll shoot.

\section{Distribution AND FreQUency OF SENTENCES With IMPLIED NeGATION}

\section{A. Distribution and Frequency of Negative Words}


TABLE 1

NEGATIVE WORDS

Chi-Square Tests

\begin{tabular}{|l|c|r|r|}
\hline & Value & df & $\begin{array}{c}\text { Asymp. Sig. } \\
(2-\text { sided })\end{array}$ \\
\hline $\begin{array}{l}\text { Pearson Chi-Square } \\
\text { Likelihood Ratio }\end{array}$ & $109.008^{\mathrm{a}}$ & 25 & .000 \\
N of Valid Cases & 119.147 & 25 & .000 \\
\hline
\end{tabular}

ROW * COL Crosstabulation

\begin{tabular}{|c|c|c|c|c|c|c|c|c|}
\hline & \multicolumn{6}{|c|}{$\mathrm{COL}$} & \multirow[b]{2}{*}{ Total } \\
\hline & & Browna & Brownb & Loba & MEE & $\mathrm{Nec}$ & T4 & \\
\hline \multirow[t]{6}{*}{ ROW } & $\mathrm{a}$ & 14 & 9 & 16 & 67 & 101 & 15 & 222 \\
\hline & ad & 2 & 3 & 1 & 34 & 17 & & 57 \\
\hline & $\operatorname{con} j$ & 7 & 4 & 14 & 86 & 97 & 7 & 215 \\
\hline & $\mathrm{n}$ & 16 & 30 & 24 & 222 & 326 & 51 & 669 \\
\hline & prep & 191 & 126 & 181 & 893 & 1189 & 180 & 2760 \\
\hline & $\mathrm{v}$ & 92 & 62 & 110 & 318 & 520 & 45 & 1147 \\
\hline Tot & & 322 & 234 & 346 & 1620 & 2250 & 298 & 5070 \\
\hline
\end{tabular}

TABLE 2

PERCENTAGE OF SENTENCES WITH NEGATIVE WORDS

\begin{tabular}{|l|l|l|l|l|l|l|}
\hline Corpus & Browna & Brownb & Loba & Mee & Nec & T4 \\
\hline NW & 322 & 234 & 346 & 1620 & 2250 & 298 \\
\hline Total & 4156 & 2612 & 4176 & 20310 & 30330 & 5084 \\
\hline Percentage & 0.077478 & 0.089587 & 0.082854 & 0.079764 & 0.074184 & 0.058615 \\
\hline
\end{tabular}

NW: sentences with negative words

TABLE3

PERCENTAGES OF NOUN, PREP, AND VERB

\begin{tabular}{|l|l|l|l|l|l|l|}
\hline Corpus & Browna & Brownb & Loba & Mee & Nec & T4 \\
\hline Npercentage & 0.04968 & 0.1282 & 0.0693 & 0.1137 & 0.1448 & 0.1711 \\
\hline Ppercentage & 0.5931 & 0.5384 & 0.5231 & 0.5512 & 0.5284 & 0.6040 \\
\hline Vpercentage & 0.2857 & 0.2649 & 0.3179 & 0.1969 & 0.2311 & 0.1510 \\
\hline
\end{tabular}

Null hypothesis: there is no significant difference between those sentences with negative words.

From table $1, \mathrm{x}^{2}=109.008$. The critical value for the five percent and $25 \mathrm{df}$ is 37.65 .

Since $x^{2}>37.65$, we can thus claim a significant difference in the distribution of sentences with negative words in the six corpora. By considering the observed and expected frequencies in the contingency table, it is possible to show that there are more sentences with negative prepositions, less sentences with negative adverbs than expected for an even distribution. Also, adjectives, conjunctions are less used than expected. Prepositions are most frequently utilized, verbs are the second and nouns the third. T4 has fewer sentences with negative words than expected. Brownb has the highest proposition of sentences with negative words, while T4 has the lowest. However, the percentage of negative prepositions in T4, 0.6040, is much higher that of the others; and the same is true for percentage of nouns, 0.1711 . While in other corpora, negative verbs are very noticeable, and the percentage is much higher than that of the nouns. But in T4, it is less than nouns. Moreover, percentage of verbs in Loba, Browna and Brownb (all belonging to journalistic writing) is higher than others. Even though sentences in Nec are largest in number, its proportion is in the middle. As for the application of preposition, out of, away from, without, instead of, against and off are most frequently used than others. While others such as above, below, beneath, and past are rarely found. From, combined with certain nouns and verbs are also widely employed. Conjunction such as unless is frequently used as well. As for adjectives, phrases like a far cry from, alien to, foreign to, Greek to and reluctant to are scarcely applied, either. Besides, adverbs like otherwise is often used, while vainly, in vain and the last/least/limit are more difficult to find that expected. In all, we can conclude that negative prepositions, nouns and verbs are frequently employed in formal language, for they can make the statement concise and terse.

TABLE 4

NEGATIVE WORDS VS CORPUS

RAW * COL Crosstabulation

\begin{tabular}{|c|c|c|c|c|c|c|c|c|}
\hline & & \multicolumn{6}{|c|}{$\mathrm{COL}$} & \multirow[b]{2}{*}{ Total } \\
\hline & & Browna & Brownb & Loba & Mee & $\mathrm{Nec}$ & T4 & \\
\hline \multirow[t]{3}{*}{ RAV } & NW & 322 & 234 & 346 & 1620 & 2250 & 298 & 5070 \\
\hline & OTHERS & 3834 & 2378 & 3830 & 18690 & 28080 & 4786 & 61598 \\
\hline & & 4156 & 2612 & 4176 & 20310 & 30330 & 5084 & 66668 \\
\hline
\end{tabular}




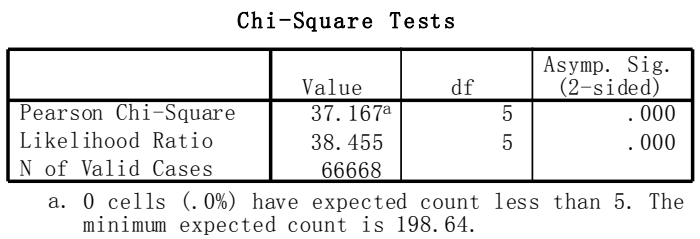

As the table shows, $\mathrm{x}^{2}=37.167$. The critical value of $\mathrm{x}^{2}$ at five percent level or $5 \mathrm{df}$ is 11.07 . Therefore, there is significant difference in the distribution of this category. According to Table 2, Browna has a high proportion of sentences with negative words, but the total number of that type of sentences is the smallest than the others, quite contrary to the observed. However, even the number of sentences in Nec and Mee is much larger than that of the others, its proportion is not the same, owing to their large corpus. Meanwhile, even though the number of sentences in T4 is larger than that of Brownb, its proportion is the lowest different from what we see. In addition, the total number of sentences with negative words is very respectable, so we should pay more attention to these types of words.

\section{B. Analysis on the Discovery}

The null hypothesis is that: there is no significant difference in the distribution of negative sentences in the six corpora. However, from the above data, we notice that all the alternative hypotheses can be accepted. Thus we can reject the null hypothesis: there is significant difference in the distribution of negative sentences in the six corpora.

Moreover, the above data indicate that implied negation in vocabulary and structure is more frequently employed in journalistic writing (as in Loba, Browna and Brownb), which, to a great extent, is influenced by the specific style of it. As is known, journalistic English, generally represented by news reporting, aims to present to a mass audience of different educational levels news in the magazine or newspaper in simple, easy-to-understand language. Owing to the limitation of space and pressure for time on the part of reader, reporters have to compress their information while making it clear and interesting. The need to be compact, clear and interesting poses particular demand on the graphological design of headlines; on the peculiar arrangement of event, and on the clarity, directness and vividness of language. (Qin, 1987)

At the level of vocabulary, journalistic writing exhibits some striking characteristics. The general trend is to use simple, accurate and vivid word so as to achieve various sentence patterns.

Negative words and structures meet the demand to some degree when negation is involved. If the reporter applies too many no-structures in his writing, his article might be monotonous and will decrease vividness and interest. On the contrary, if those negative words and structures are utilized properly, the compactness and expressiveness will be strengthened. Thus, it is the demand of journalistic writing that prompt the application of more negative words and structure than those in other corpora, which, too, explains why the percentages of verbs in the three journalistic corpora are much higher than those of others.

Meanwhile, it is the same cause for the less distribution of negative words in T4 corpus. EST writing aims for a plain, clear, concise and accurate style and structure. EST sentences are logical in their meaning and their relationship to each other. Two main features of EST in style and structure are conciseness and conditions (restrictive). Conciseness is one of the most essential features of EST in style and structure. The restriction reflects another important features of EST in style and structure. It makes the meaning more accurate (Dai, weihua, 1984). Obviously, these two features emphasize on concision and precision instead of the vividness or variation of sentence patterns, let alone attraction of its content. That is, EST writing pays no attention to how to make the language interesting or how vivid the language is. Accordingly, it will apply less implied negatives, as direct negation is enough to make the point clear. Nevertheless, owing to its conciseness, more prepositional phrase and nominalization are intended to be employed, which clarifies why negative prepositions and nouns are exploited more than other attributes in T4 corpus.

To sum up, the choice of application of negative words or structure is subject to the style of the relevant essay.

\section{REFERENCES}

[1] Bolinger, D. (1977). Meaning and Form, London: Longman.

[2] Cruse, D.A. (2000). Meaning in Language:An Introduction to Semantics and Pragmatics. New York: Oxford University Press.

[3] Dai,weihua. (1984). EST-English for Science and Technology, Shanghai: Shanghai Foreign Language Education Press.

[4] Downing, L.H. (2000). Negations, Text World and Discourse, the Pragmatics of Fiction. Ablex Publishing Corporation Stamford, Conntiut

[5] Fasold, R. W. (1990). The sociolinguistics of Language. Oxford: Basil Blackwell.

[6] Givon, T. (1993). English in Grammar: a function-based Introduction. Amsterdam: John Benjamins Pub, Co.

[7] Grice, H.P. (1975). Logic and Conversation. In P.Cole and J.L. Morgan (eds).

[8] Halliday, M.A.K. (1994). An Introduction to Functional Grammar. London: Edword Arnold.

[9] Halliday, M.A.K.and Husan, R. (1985). Language, co ntext, and Test: a social-semiotic perspective. Language and Learning (3). Geelong, vic: Deakin University Press.

[10] Huddleston, R. (1984). Introduction to the Grammar of English. Cambridge: Cambridge University.

[11] Jesperson, O. (1917). Negation and Other Language. Danske Videnskemperson, Copenhagen. 
[12] Klima, E.S. (964). Negation in English, in Fodor and Katz (eds). The structure of Language. Englewood Cliff, N.J.: Prentice-Hall.

[13] Leech, G.N. (1971). Meaning and the English Verb. London, Longman,

[14] Leech, N.G. (1983). Semantics. New York: Longman.

[15] Lyon, J. et al. (1987). New Horizons in Linguistics, 2. London: Penguin Books.

[16] Lyons, J. (1977). Semantics, 2 volumes. 1977. Cambridge: Cambridge University Press.

[17] Lyons, J. (1995). Linguistic Semantics. Foreign Language Teaching and Research Press; Cambridge Press.

[18] Pan, Huanhuai. (1984). Modern English Syntax. Beijing: Beijing Normal University Press.

[19] Qin Xioubai. (1987). A Survey of Stylistics. Hu Nan: Hu Nan Education Press.

[20] Quirk Randalph, et al. (1985). A Comprehensive Grammar of the English Language. New York: Longman world Publishig Corp.

[21] Seifert, S and r Welte,W. (1987). A Basic Bibliography on Negation in Natural Language. Gunter Narr Verlag, Tubingen.

[22] Tottie, G. (1991). Negation in English Speech and Writing: a Study in Variation. New York: Academic Press, INC.

[23] Wang, Fengxin. (1989). A Notional Grammar of Englilsh. Beijing: Beijing University Press.

[24] Xiong, jianheng and Zhao, zhixia. (1985). A Practical English Grammar for Communication. Shanghai: Shanghai Translation Press.

[25] Xu Youzhi. (1992). Modern English Stylistics. He Nan: He Nan University Press.

[26] Xu, Guanglian. (1998). College English Grammar. Wu Han: Huadong University of Technology.

[27] Zeng, Zhaozhi, (1995). Negation in English. Wu Han: Wu Han University Press.

Yun Ding was born in Qingdao, China in 1976. She received his M.A degree in linguistics from Dalian Maritime University, China in 2003.

She is currently lecturer in Foreign Languages Department, Qingdao University of Science and Technology, Qingdao, China. Her research interests include applied linguistics and language teaching. 